\title{
Could Java Change Everything? The Competitive Propriety of a Proprietary Standard1
}

\author{
Mark A. Lemley2 \& David McGowan3 \\ "The software industry is about the politics of standardization" \\ -- attr. Ted Nelson4
}

What should be done about Microsoft? The question is on everyone's lips these days, it seems (at least, everyone interested in antitrust law, intellectual property, or the computer industry). Even asking the question infuriates some, for whom government intervention in the marketplace is anathema under any circumstances. Others think the only solution is to break up the company, or at least take away its exclusive ownership rights to its operating system code.5 The Antitrust Division has steered a middle ground, monitoring conduct at the periphery of Microsoft's market power but not seeking to break it up.6 Regardless of one's approach, the central question in antitrust today seems to be what to do about a firm with durable market power across numerous product generations in an important sector of the economy.

1 Copyright 1998 David McGowan \& Mark A. Lemley.

2 Assistant Professor, University of Texas School of Law; of counsel, Fish \& Richardson P.C., Austin, Texas.

We would like to thank Jonathan Band, Michael Froomkin, Rose Hagan, and Miranda McGowan for comments on an earlier version of this draft.

3 Director, Howard, Rice, Nemerovski, Canady, Falk \& Rabkin, San Francisco, California; Lecturer, Boalt Hall School of Law, University of California at Berkeley.

4 Phil Agre, The Internet and Public Discourse <http://communication.ucsd.edu/pagre/> (quoting Ted Nelson).

5 See infra note _..

6 Predictably, this compromise approach has pleased virtually no one on either side, though it may in fact be the most measured response. See infra notes ____ and accompanying text. 
We suspect it is the wrong question. Microsoft's power in the operating system market is a function of two factors. First, intellectual property law gives Microsoft property rights in its code. These rights include the power to preclude others from copying its code and perhaps its application program interfaces as well. Thus, Microsoft's operating systems are unique products that cannot easily be duplicated. Second, the operating system market is characterized by strong (albeit virtual) network effects,7 meaning that users will naturally gravitate towards a single standard platform and tend to stay there. So long as these two facts do not change, antitrust can do little to open the operating system market to effective competition.8 At this point in the history of computing, the economic characteristics of operating systems dictate a platform-dependent competitive paradigm.

By contrast, if each consumer could operate across platforms, exchanging data with other consumers regardless of the operating system they used, it is quite easy to imagine robust competition in the operating systems market. Network effects would still drive consumers to the same standard, but that standard could embrace multiple platforms. Consumers could choose between IBM, Apple, Sun, Linux and Microsoft operating systems on their merits as programs, and not on the basis of what everyone else uses, or what compatible applications programs exist. In a world in which the platform from which one operates is irrelevant to one's ability to exchange data, the sheer number of existing platform users will be much less important to a consumer's purchasing decisions.

7 For more on this definition, and network effects in general, see Mark A. Lemley \& David McGowan, Legal Implications of Network Economic Effects, 86 Cal. L. Rev. _ (forthcoming 1998); S.J. Liebowitz \& Stephen E. Margolis, Network Externality: An Uncommon Tragedy, 8 J. Econ Persp. 133 (1994); Michael L. Katz \& Carl Shapiro, Network Externalities, Competition, and Compatibility, 75 Am. Econ. Rev. 424 (1985); Joseph Farrell and Garth Saloner, Standardization, Compatibility, and Innovation, 16 Rand J. Econ. 70 (1985).

8 For elaboration on this point, see Mark A. Lemley, Antitrust and the Internet Standardization Problem, 28 Conn. L. Rev. 1041 (1996). 
Enter Java, which is described by its owner, Sun Microsystems, as "a standardized application programming environment that affords software developers the opportunity to create and distribute a single version of programming code that is capable of operating on many different, otherwise incompatible systems platforms."9 Thus described, Java offers the promise of platformindependent computing, the equivalent of a standardized "meta"-operating system that would allow both consumers and programmers to choose operating systems free of the constraints of network effects. Java may reduce the opportunity cost incurred by those using platforms other than the market standard, thereby facilitating transition among platforms and alleviating concerns that Microsoft can exploit its installed base of users and programmers.

But promise is not necessarily reality. In this Article, we examine the implications Java has for competition in operating systems and related software markets. Part I offers a very brief review of network effects and their implications for antitrust.10 Part II considers the implications of network effects on the operating system market absent Java, using as a vehicle the Antitrust Division's recent case against Microsoft. Finally, Part III considers whether Java might ameliorate the problems identified in Part II, and the extent to which it might raise new antitrust problems of its own.

9 Sun Microsystems v. Microsoft, Complaint, No. __ II 2 (N.D. Cal. 1997). As noted below, "Java" can actually refer to a number of different components of a system, including an operating system, a programming language, and a "virtual machine." See infra notes ___ and accompanying text.

10 This part is not intended as an introduction to the field. We assume some familiarity with the idea of network effects. For more detailed descriptions of the economics, see Michael L. Katz \& Carl Shapiro, Network Externalities, Competition, and Compatibility, 75 Am. Econ. Rev. 424 (1985); S.J. Liebowitz \& Stephen E. Margolis, Network Externality: An Uncommon Tragedy, 8 J. Econ Persp. 133 (1994). On the law of network effects, see Lemley \& McGowan, supra note 


\section{I. "NETWORK EFFECTS" AND THE THEORY OF INCREASING RETURNS ${ }^{11}$}

Software, and in particular operating system software, is commonly said to exhibit positive "network externalities," a term defined by Professors Katz and Shapiro to refer to cases in which "the utility that a user derives from consumption of" software "increases with the number of other agents consuming the good."12 In other words, a network effect exists where the purchaser finds a good more valuable as additional purchasers buy the same good. Professors Farrell and Saloner include in their definition situations in which "one consumer's value for a good increases when another consumer has a compatible good,"13 though in such cases the network effect may be influenced by competition among firms providing compatible goods. Farrell and Saloner therefore refer to network effects in compatible goods as "market mediated" effects. ${ }^{14}$ The balance of this article is devoted in significant part to analyzing the vitality of competition in this "market mediated" segment of the software world.

Within network effects, we follow Katz \& Shapiro's general distinction between "actual" network effects, "virtual" network effects, and positive feedback effects. ${ }^{15}$ These different network

\footnotetext{
${ }^{11}$ The following discussion draws on Lemley \& McGowan, supra note __.

${ }^{12}$ Michael L. Katz \& Carl Shapiro, Network Externalities, Competition, and Compatibility, 75 Am. Econ. Rev. 424 (1985). Katz and Shapiro, as well as most economists, use the term "network externality" to describe this phenomenon because the benefit conferred by additional users of a good on those who already own the good meets the economic definition of an "externality"--the effect (positive or negative) of an action on someone other than the actor. Because the term is most often used in legal parlance to indicate a situation in which legal action should be taken to "internalize" the externality, we here use the more neutral term "network effect," as have some economists writing in this field. See S.J. Liebowitz \& Stephen E. Margolis, Network Externality: An Uncommon Tragedy, 8 J. Econ. Persp. 133, 135 (1994).

${ }^{13}$ Joseph Farrell and Garth Saloner, Standardization, Compatibility, and Innovation, 16 Rand J. Econ. 70 (1985).

${ }^{14} \mathrm{Id}$.

${ }^{15}$ See id. at _..
} 
effects may be of different strength, and may have different consequences. ${ }^{16}$ One feature of actual networks--such as communications or transportation systems--and strong virtual networks--such as an operating system--is that returns to scale are likely to increase throughout most if not all of the range of demand. Each consumer will enjoy some marginal benefit for nearly every additional purchaser of a computer utilizing a given operating system. The marginal benefit may be low, and may diminish as the network grows, but it will be positive.

Another difference relevant to software markets is that in order to provide utility to consumers software must interoperate in a more complex and closer manner than many other combinations of goods. At bottom, software consists of binary code, sequences of 0's and 1's that instruct a computer to turn electronic switches on and off. ${ }^{17}$ To simplify matters for the moment, we can divide the universe of code into operating systems code, which manages the internal functions of a computer such as storing or retrieving data, communicating with modems and printers, and the like; and applications code, which performs such familiar functions as word processing or spreadsheet operations. ${ }^{18}$ To provide consumers with the computing functions they

\footnotetext{
${ }^{16} \mathrm{We}$ pause here to emphasize that our discussion of network effects in software is limited to operating systems. Though applications, such as Netscape Navigator or Lotus 1-2-3, enjoy the same scale economies as all software, historical evidence to date suggests that network effects--increasing returns attributable to demand-side factors-are much weaker for applications than for the operating system. Thus, Lotus and then Borland lost their once-dominant positions to Microsoft Excel, and Netscape Navigator appears to be losing its once-dominant position as well. This observation must in turn be qualified, because in each case the market share shifted to Microsoft, which enjoys strong network effects in the operating system. Each of these examples involved a test of the strength of network effects in the application and in the operating system. While we can say that network effects in applications may be weak relative to the operating system, we cannot assess their strength in the abstract.

17 For a general, accessible discussion of the technology, see Peter S. Menell, Tailoring Legal Protection For Computer Software, 39 Stan. L. Rev. 1329 (1987).

18 Id. As discussed in more detail in Section II, the line between operating system code and applications code is neither clear nor static; the actual market is much more complex than the simplified model described above.
} 
desire, applications and operating systems code must interact in as seamless a manner as is possible. Achieving such interoperability is a considerably more complex task than, say, establishing standard sizes for tires and rims on cars, or determining the number of prongs an electric plug should have.

These facts carry significant implications for business strategy for the Internet, which in large part is comprised of two very strong network goods: telephony infrastructure and computer software. One would therefore expect returns on goods that facilitate use of the Internet to increase with demand. For example, the value of the protocols that fundamentally define the Internet clearly increases as additional users join the Internet. So too does the value of Microsoft's operating system increase as more and more people choose to use it. The difference between the two is that the TCP/IP protocol underlying the Internet is open (and indeed free), while Microsoft's proprietary operating system standard is "closed" to competitors.

From the perspective of competition policy, the prospect of increasing returns has been suggested as a reason to rethink the rationality of behavior, such as predation, considered unlikely to reduce social welfare under an assumption of decreasing returns. Increasing returns also may introduce new antitrust problems of their own. We outline a few such problems here.

\section{A. Market "Tipping" and "Lock-In"}

Network theory implies that strong network markets will tend to "tip" to a standard technology because a large portion of the value of goods in such markets is, by definition, to communicate with others who own the standard as well or to interoperate with goods compatible with the standard. The relatively high network value and low inherent value of such goods implies 
that, once consumers perceive that a de facto standard has been established, tipping will occur very quickly. ${ }^{19}$

Market share or, more precisely, consumers' expectations of a firm's market share, is therefore likely to have independent competitive significance in network markets. If consumers perceive themselves to be operating in a strong network market, it is only natural for them to use market share as guide for predicting which product will prevail in a standards competition. Because consumers will not want to be stranded with non-standard technology, market share alone may be a persuasive selling tool. Not surprisingly, firms in such markets contest claims of relative market share vigorously, sometimes through the courts. ${ }^{20}$ And where actual market share data is not available (ie. where the product in question is new), consumers may rationally look to past results as an indicator of future performance.

The stronger the network effect, the more likely it is that consumers will prefer either one or only a very few "standard" products and the harder it will be for consumers to transition from an existing standard to a new one. In addition to standard switching costs, which are common in many durable goods markets, consumers in network markets incur opportunity costs in switching to a new standard: they may lose the ability to interoperate with consumers on the old standard and have fewer complementary goods to choose from. The prospects of opportunity costs presents a familiar collective action problem. Because the costs will be lower to consumers who switch to a new standard after it becomes relatively popular--interoperability will be less

\footnotetext{
19 Professors Katz and Shapiro summarize the problem this way: "Because of the strong positive-feedback elements, systems markets are especially prone to "tipping," which is the tendency of one system to pull away from its rivals in popularity once it has gained an initial edge." Katz \& Shapiro, supra note 25, at 106.

${ }^{20}$ WordPerfect once sued Microsoft over the latter's claim that its word processing software was the most popular in the world. Shapiro, Antitrust In Network Industries, supra note 42. Credit cards are also relatively strong network goods, and Visa's advertising campaign ("and they don't take American Express") is designed to take maximum advantage of this fact. See Lemley \& McGowan, supra note 9, at __.
} 
constrained and complementary goods more plentiful--consumers may rationally adhere to an existing standard hoping that others will incur the relatively high initial costs of transition to a new standard. If this collective action problem is severe, consumers may be "locked in" to the existing standard and, if the existing standard is suboptimal, social welfare may suffer.

Tipping is neither inherently good nor bad. If the economics of a particular market dictate that having one standard is more efficient than competition among systems, then "tipping" to a standard is, in theory and absent significant transaction costs or some form of regulation, all but inevitable. In such circumstances a market that converged on the best product in a standards competition would be efficient (capturing positive externalities to the greatest extent possible) and therefore desirable; efforts to forestall tipping would create losses in terms of unrealized efficiencies, thus reducing social welfare. Even if an "inferior" product won the standards competition, that outcome may still be more efficient than a failure to select any standard at all, since consumers would get the network benefits of using products that could interoperate.

Nor should we lightly conclude that a standard consumers adopt is suboptimal. Though even in markets where standardization maximizes social welfare there is at least a theoretical risk that the "wrong" standard will be adopted (or, more likely, that a standard which was optimal when adopted will become relatively suboptimal over time), ${ }^{21}$ the choices of consumers in the market are entitled to considerable respect. ${ }^{22}$ A conclusion that consumers have chosen the "wrong" standard should not be drawn absent evidence that an existing standard is in fact suboptimal. By the same

${ }^{21}$ See Michael L. Katz \& Carl Shapiro, Systems Competition and Network Effects, 8 J. Econ. Perspectives 93, 106 ("standardizing on a single system can be very costly if the system selected turns out to be inferior to another system").

22 See David McGowan, Regulating Competition In The Information Age: Computer Software As An Essential Facility Under The Sherman Act, 18 Hastings Comm./Ent. L.J. 771, 845 (1996). 
token, however, evidence that an owner of a potential proprietary standard has taken action to bias the choice, or that the owner of an existing standard has acted to increase the costs of transition among standards, may be evidence that the standard thus chosen is not the socially optimal one. Though not all actions taken to defend a standard necessarily call for an antitrust remedy -- indeed, many will be welfare-enhancing -- standards competitions warrant careful legal scrutiny of potential anticompetitive conduct. 23

\section{B. Predation and Leverage Tying}

Network markets by definition offer potentially lucrative returns to firms that can establish a proprietary good as a standard on which competition in the market, or in aftermarkets for complementary goods, will be based. ${ }^{24}$ Whether a good becomes a standard depends in significant part on whether consumers expect the good to become a standard: nobody wants to own a Betamax in a VHS world and, if VHS manufacturers can persuade consumers that VHS will be the standard, the prophecy is likely to be self-fulfilling. The combination of increasing returns and consumer sensitivity to competition between rivalrous "standards" presents the possibility of material firstmover advantages.

Being first into a market in which consumers will seek to purchase the prevailing standard may confer an important advantage over later entrants. ${ }^{25}$ Because the returns to the standards

23 See Lemley, supra note __, at __.

${ }^{24}$ Stanley Besen \& Joseph Farrell, Choosing How To Compete: Strategies and Tactics in Standardization, 8 J. Econ. Persp. 117, 119 (1994).

${ }^{25}$ Besen \& Farrell, supra note 35, at 122. Of course, this advantage is not absolute. The first entrant in the VCR market, the Sony Betamax, ended up losing the standards competition. 
winner will be higher than in "normal" markets, relatively risky strategies such as predation or, at a minimum, penetration pricing, might be rational in a networks market. Predation has quite reasonably been considered an unlikely threat to social welfare because a firm pursuing the strategy would have to recoup predatory losses by raising prices, which in turn would induce entry limiting the firm's ability to recoup. Because returns in strong network markets increase with demand, however, and because consumers' reluctance to abandon the dominant standard may deter entry, ${ }^{26}$ recoupment of losses incurred in predating may be easier than has been presumed to be the case in non-network markets. ${ }^{27}$

Increasing returns also raise questions about the possibility of effective leveraging, an argument most commonly associated with antitrust tying claims. Analysts working from a Chicago orientation have argued that leveraging is unlikely because a given amount of monopoly power can extract only a given amount of revenue from consumers, whether taken all in the monopolist's primary market or split between that market and some other. ${ }^{28}$ This view has been challenged even

\footnotetext{
${ }^{26}$ At a minimum, a firm contemplating entry would have to discount prospective returns more heavily to account for the risk that consumers would not buy the entrant's product even if they favored it over an inferior standard product. The estimated returns themselves might be larger than in a non-network market, however; no a priori conclusions may be drawn from network theory alone.

27 See Lemley, supra note _, at 1074-75 ("to the extent that standardization effects create a significant barrier to entry in software markets once a market standard has been established, they may make recoupment (and therefore predation) more likely"); Besen \& Farrell, supra note 33, at 123.

${ }^{28}$ E.g., Robert H. Bork, The Antitrust Paradox: A Policy At War With Itself 372-75 (2d ed. 1993); Richard A. Posner, Antitrust Law: An Economic Perspective 172-73 (1976). Indeed, even analysts not wholly within the Chicago School have expressed skepticism for the leverage theory of tying. E.g. Herbert Hovenkamp, Federal Antitrust Policy, The Law of Competition, And Its Practice $\$ 7.6$ (1994).
} 
without regard to network theory, ${ }^{29}$ but the possibility of leveraging into or from a network market raises additional questions worthy of careful consideration, particularly with respect to the risk of tying across generations of a product or newly-introduced complementary goods. ${ }^{30}$ Professor Shapiro summed up this concern while Deputy Assistant Attorney General at the Antitrust Division:

[T]he primary method by which today's network monopolist can maintain its monopoly may well be to extend its control, at least in part, to the next generation of technology.... [A]ntitrust concerns quickly arise when a firm controlling the standard in one product area uses its dominance to set and control the standard for the next generation of that product, or for a second, complementary product. This leveraging strategy includes situations where a firm controlling one product incorporates a second product into its offerings and extends its control to the second product. $^{31}$

Even if leveraging is more likely to succeed where a network market is on one side or the other of a tie, however, it does not necessarily follow that social welfare would be diminished. Assuming the markets in question involve proprietary goods, and that the relevant network effects

${ }^{29}$ See Louis Kaplow, Extension of Monopoly Power Through Leveraging, 85 Colum. L. Rev. 515 (1985) (arguing that leveraging can enhance monopoly profits in cases involving market imperfections). The notion that a monopolist possesses only a fixed amount of monopoly power at any given point in time is of course true, and to say that dividing such power into more than one market will reduce the amount expended in the original market is true by definition. As Professor Kaplow points out, however, when one analyzes competition over time the mathematical precision of static analysis falls away. It is in theory possible for a tying arrangement to allow a firm to reach $\mathrm{T}_{2}$ with greater power than it had at $\mathrm{T}_{1}$, or to retain the same amount of power in the face of circumstances that otherwise would have eroded power over time. This possibility by no means justifies hasty conclusions that leveraging is likely, or common, or even reliably recognizable. It does, however, justify the caution that the precision of static analysis, and the certainty of static conclusions, does not transfer to dynamic analysis.

${ }^{30}$ See Lemley, Internet Standardization, supra note 38, at 1069; McGowan, supra note 34 at 847.

${ }^{31}$ Carl Shapiro, Antitrust In Network Industries <http://www.usdoj.gov/atr/speeches/shapir.mar>. 
in both markets are relatively strong, then one or only a few standard goods are likely to survive in either market anyway. That a firm achieves a large market share in such a market does not, in and of itself, warrant condemnation. Rather, the question from a social welfare perspective is whether the standard so selected is the optimal one. More importantly, the question is not just which standard was technically "better," but also whether the firm managed to force the adoption of a proprietary standard in place of an open one. If so, it may have eliminated intra-standard competition that would otherwise exist, and thus reduced social welfare. On top of this should be layered another concern: that leveraging could stifle innovation, thereby denying consumers the benefit of more dynamic technology and undermining the goal the copyright laws seek to achieve by awarding property rights in software in the first place.

\section{II.THE (POSSIBLY) CHANGING PARADIGM OF COMPETITION IN PERSONAL COMPUTING: BROWSER WARS AND JAVA WARS}

One of the most interesting aspects of applying legal or economic principles to the Internet is their relentless indeterminacy, particularly in light of the dynamic state of competition in markets for Internet applications. Firms find it hard to know which side of a given debate will further their interests; occasionally firms find themselves on both sides simultaneously. Consider the following statements, both from Microsoft:

'They [Sun] are trying to have their cake and eat it too,' said Charles Fitzgerald, a group program manager at Microsoft. 'It comes down to: Can a single company be trusted to control a standards process? The answer is they can't.'32

32 N.Y. Times, [cite]. 
Permitting the hundreds of computer manufacturers around the world who license Windows 95 to decide for themselves what parts of the operating system they will and will not ship would destroy the common benefits of that common platform. . . . Microsoft avoids problems associated with such balkanization by requiring computer manufacturers ... to ship Windows 95 the way it was designed.33

The first quotation refers to Microsoft's criticism of Sun's efforts to have Java certified by the International Organization for Standardization (ISO) as an international standard. ${ }^{34}$ The second is taken from Microsoft's memorandum in opposition to the petition by the Antitrust Division for an order holding Microsoft in contempt of its 1995 consent decree with the Justice Department. ${ }^{35}$ The apparent contradiction in these statements ${ }^{36}$ is not the result of inadvertence, corporate confusion, or poor legal advice. Microsoft did not achieve its market position through chance or ignorance. It is the economics of market structure and rational competitive strategies that produce such issue-straddling.

33 United States v. Microsoft, Microsoft's Memorandum in Opposition.

${ }^{34}$ One may track much of the history of these efforts at <http://java.sun.com/aboutJava/standardization/index.html>, Sun's Java standardization web site. The term "ISO" is not an abbreviation for the International Organization for Standardization, but is instead derived from the greek "isos," meaning of equal dimensions (an "isosceles" triangle).

The organization adopted ISO in part because a formal abbreviation of its name (IOS) did not translate in the proper sequence into French, one of ISO's three official languages. <http//www.iso.ch/infoe/intro.html>. Whether this is something of a metaphor for the standardization process itself is a question beyond the scope of this article, but worth contemplating nevertheless.

${ }^{35}$ The papers in this case are available from many sources, including <http://www.usdoj.gov/atr>.

${ }^{36}$ Microsoft would likely take issue with the comparison in the text on the ground that its operating system is not an international standard, or at least not the type of standard for which Sun seeks approval. While formally correct, to the extent network effects are strong with respect to operating system software the distinction may be one with little difference. 
At present, personal computing is dominated by Microsoft's operating systems--DOS and various iterations of Windows. ${ }^{37}$ A variety of software applications work with the operating system to provide utility to consumers--from word processing to spreadsheets to home banking, and beyond. Applications written for one operating system, however, will not automatically run on others: one may run Excel for Windows on Windows and Excel for Macintosh on a Mac, but they may not be switched. And increasingly, applications programs are written only for one operating system platform -- generally Microsoft's, since it has most of the market.

Principles of network theory suggest what market history bears out; Microsoft's hold on the operating systems market has strengthened as consumers have recognized Microsoft's operating system products as de facto standards and have gravitated to them. Microsoft has shrewdly expanded this installed base of users to gain ascendance in applications markets--word processing and spreadsheets, for example--previously dominated by other firms, such as WordPerfect and Lotus. $^{38}$

The idea of using the operating system installed base to strengthen one's position in adjacent markets certainly did not start with Internet Explorer. But this history does not automatically

\footnotetext{
37 Windows is in fact a "shell" of code operating on top of DOS and providing graphical user interface capability. Though Microsoft does not highlight the fact in its advertising, its brief in opposition to the Antitrust Division's contempt petition emphasizes that Windows is comprised of distinguishable products: "even after their functionality was merged into Windows 95, MS-DOS 6 and Windows 3.1 continued to be offered separately to computer manufacturers." [cite] The Antitrust Division's petition claims that Microsoft estimates that $80 \%$ of personal computers sold in the United States between mid-1996 and mid-1997 will come with Microsoft operating systems preinstalled. Published estimates of Microsoft's operating systems market share are generally in this range.

${ }^{38}$ For general discussions of this point see Knowing the ABC's Of the Antitrust Case Against Microsoft, Wall St. J. October 30, 1997; Why Software and Antitrust Law Make An Uneasy Mix, Wall St. J. October 22, 1997.
} 
compel the conclusion that such "leveraging" reduces social welfare; the question depends on the conduct at issue in each case. Microsoft's ascendance with respect to each application has generally had to wait for its particular product, such as Word or Excel, to reach a level of quality roughly equal or superior to its competitors. This may be the case now with Internet Explorer, which has received favorable reviews from many analysts. ${ }^{39}$ Indeed, even when Microsoft's principal competitor announced that it would match Microsoft's tactic of giving its browser away free of charge, hardware manufacturers, who install browsers on new computers, appeared to prefer Internet Explorer. $^{40}$

Microsoft does have at least a potential advantage in its ability to achieve seamless integration of its application software with its own strong network good--the operating system. If we are concerned about leveraging, it follows that Microsoft's conduct should be watched carefully. It does not follow that Microsoft should be broken up, with its operating system spun off to be produced by a firm distinct from its applications, ${ }^{41}$ or that its efforts to migrate the installed base for

39 E.g., Face Off, P.C., November 18, 1997100 ("IE4 offers the richest browsing experience, even without its optional desktop integration, about which we have decidedly mixed opinions"); Microsoft's Cool New Browser, Fortune October 27, 1997260 ("[Internet Explorer 4.0] is fast, efficient, and so chalk [sic] full of improvements that it beats Navigator hands down"); Browser Worth Browsing, Bus. Week, October 20, 199722 ("The browser component of IE 4.0 builds on Microsoft's already good version 3.02 and is at least the equal of Netscape Navigator 4.0").

${ }^{40}$ David Einstein, Netscape Browser to be Free, S.F. Chronicle January 25, 1997 at B1 (noting "three of the top PC companies said they have no plans to switch, claiming their customers prefer Microsoft's browser").

41 Some have suggested that the Antitrust Division pursue a breakup remedy akin to the Division's case against AT\&T. See It's Gates vs. Reno, S.F. Chronicle October 22, 1997, at B2; Is Smart Bet on DOJ in Latest Microsoft Spat?, S.F. Recorder, October 22, 1997, at 2. To the degree such suggestions presume that a fragmented Microsoft would result in a less integrated operating system, they present the risk of reducing social welfare by attempting to counter the strong network effects--which is to say limit the positive externalities associated with the operating system-that may prompt the suggestions in the first instance. 
its operating systems to its applications necessarily diminish social welfare. To the extent Microsoft's applications are equal or superior to competitive applications, superior integration into Microsoft's operating system might enhance social welfare.42 The effect on social welfare will depend on the conduct at issue, rather than the existence of the installed base as such. Social welfare losses are more likely to appear in the form of diminished innovation in application software, and it is this aspect of competition that must be watched most closely.

Focusing on innovation should also focus our attention on alternatives to the present market structure: the present paradigm of operating system dominance is not the only paradigm in which software markets may function. Operating systems are the key to the present structure of the market because applications do not function across different platforms. The platform a consumer uses therefore largely determines the array of applications available. If the market produced devices enabling applications to operate efficiently on a variety of different platforms--platform independence--then consumers could choose the operating system they preferred without sacrificing the benefits of adherence to a single network standard. Operating systems would be merely products that competed on their own merits to individual consumers, rather than standards to which consumers desired to adhere to obtain access to the greatest number (and most sophisticated) applications. The rapid increase in popularity of the Internet and the Web poses a potential threat to the existing platform-dependent paradigm; the appearance of Java--in Sun's terminology a

42 Specifically, one would have to weigh the social value of better integration (and therefore of improved performance) against the harm caused by giving Microsoft effective control over that applications program market. The latter harm is in turn a function of whether competition in the market would have flourished absent the linkage. 
"standardized application programming environment," ${ }^{43}$ by which is meant in essence a platformindependent meta-operating system--poses a potentially greater threat to the existing paradigm. In each case the key is whether the market can transition to a common standard allowing vertical and horizontal interoperation, and thus capturing positive externalities, without the standard itself becoming a force limiting competition. 44

A. The Browser Wars, The Microsoft Contempt Proceeding, And The Notion of Temporal Tying

While in theory any computer with a wire connection running the TCP/IP protocols is "on the Internet," in fact most ordinary mortals access the World Wide Web (the graphical user interface overlaying the Internet) using a "browser." The Antitrust Division describes the browser in its contempt petition as follows:

As the Web grew in size, users needed a convenient method of searching for, retrieving, and viewing HTML documents on the Web. In response to this need, a group of software engineers at the National Center for Supercomputer Applications developed a software application that provided the interface for accessing and reviewing HTML documents. This application, which is stored on the user's computer became known as an Internet browser. When a user wishes to view an HTML document, the browser transmits the request for the particular HTML

43 The quoted language is taken from Sun's complaint against Microsoft for violation of the Java licensing agreement between the two. The complaint and related documents are available at <http://java.sun.com/aboutJava/index $>$. The licensing agreement is available both at Sun's site and at <www.microsoft.com>.

44 One might also discern a third "war" -- between Microsoft's Windows NT and the open Unix platform as standards for server software. See Tom Quinlan, Unix, NT Set to Battle for Server Supremacy, Austin Am.Statesman, Nov. 24, 1997, at C1, C3. The outcome of the Java wars will presumably have some effect on Unix/NT competition as well. 
document to another computer on the network called a Web server. When the browser receives the HTML document from the Web server, it processes the HTML codes in the document and displays the resulting text, graphic images, and other content on the user's computer. ${ }^{45}$

Under this view of the world, browsers are complementary goods to operating systems, on the one hand, and to both the Internet (browsers can be used to transmit ordinary e-mail) and the Web on the other. The significance of browsers, however, may extend well beyond the usual positive feedback effect associated with complementary goods in software markets. Whether browsers in fact achieve such significance depends in large part on innovation in browser technology.

One vision of the competitive horizon is articulated by the Antitrust Division in the introduction to its contempt petition:

Internet browser technology, as developed by companies competing with Microsoft, may be an important element in the reintroduction of competition to the PC operating system market. . . . browsers and the technology they incorporate can serve as a platform to which applications can be written and accessed without regard to the identity of the underlying operating system. The development of application programs that are written to run on or through an Internet browser, which can itself run on any operating system, is a serious threat to Microsoft's monopoly, which stems from and is reinforced by the overwhelming base number of software

45 Memorandum of the United States In Support of Petition For An Order To Show Cause Why Respondent Microsoft Corporation Should Not Be Found In Civil Contempt ("Memorandum"), available at <http://www.usdoj.gov/atr>. "HTML" refers to Hypertext Markup Language, in which Web content is created. 
application programs that have been written specifically to work with Windows $95^{46}$

Thus, the government's theory is that the browser is a first step towards a meta-operating system that will allow users to bypass the closed standard of Windows, using whichever operating system they prefer on the technical merits. The Division's reference to monopoly power that "stems from and is reinforced by the overwhelming base number" of complementary programs available for Windows 95 is of course a pure application of network theory to the law.

On this view, the competitive stakes in the browser market are quite high. To the Antitrust Division, the browser market presents an opportunity to reintroduce competition in the operating systems market in two ways: "first, the degree to which browsers become accepted as an interface; and second, the extent to which they can serve as a platform to which applications can be written that are independent of the underlying operating system." ${ }^{47}$ It is for this reason that the Antitrust Division sought to hold Microsoft in contempt of its 1995 consent decree.

There are many issues unique to the contempt proceeding context that are not particularly relevant to a broader analysis of competition policy; because a consent decree is construed as a contract, $^{48}$ a significant portion of the papers on both sides were devoted to arguing about the context and drafting of the decree. With respect to its browser allegations, however, the decree merely allowed the Division to move quickly: the Division's allegations themselves presented a straightforward claim of unlawful tying of Microsoft's Internet Explorer to Windows 95. And

\footnotetext{
46 Memorandum, supra note 58.

47 Memorandum, supra note 58.

48 United States v. ITT Continental Baking Co., 420 U.S. 223 (1975).
} 
indeed Judge Jackson's preliminary injunction was granted not on the basis that Microsoft was in contempt of the 1995 decree, but on the alternative ground that Microsoft was probably violating the antitrust laws by tying the two products. ${ }^{49}$

Tying traditionally requires proof of four elements: the existence of two separate product markets, a tie between the two markets, market power in the tying product market, and a significant threat to competition in the tied product market.50 It seems reasonably clear that Microsoft's insistence (which it did not deny) that computer manufacturers install Internet Explorer on computers they ship if they also wish to install Windows 95 effectively tied a product in which Microsoft did not have market power (the browser) to one in which Microsoft should be presumed

49 United States v. Microsoft, _ F. Supp. __ (D.D.C. Dec. 11, 1997). It should in fairness be reiterated, however, that a significant portion of Microsoft's defense to the original contempt petition rests on the negotiating history, context, and knowledge of the Antitrust Division at the time the consent decree was entered. Such defenses are entirely appropriate to a contempt proceeding, which seeks to enforce the decree itself rather than general principles under the Sherman Act. If Microsoft's interpretation of the consent decree is correct, it may well be entitled to prevail in the original contempt proceeding, regardless of the outcome of the underlying antitrust analysis.

The same cannot be said of the second contempt proceeding filed by the Division, this one based on Judge Jackson's December 1997 order. Just three days after Judge Jackson preliminarily enjoined Microsoft from conditioning the same of any version of its operating system on the preinstallation of a Microsoft browser, Microsoft announced plans to do just that. It offered consumers the choice of either a two-year-old version of Windows 95 without Internet Explorer, or a modern version of the operating system with Internet Explorer attached. Steve Lohr, Microsoft to Appeal Ruling on Browser, Seeing 'Error', N.Y. Times, Dec. 16, 1997, at C2. Microsoft later backed off under the threat of contempt sanctions, agreeing to abide by Judge Jackson's interim order. Steve Lohr, Browser War: A Concession and a Push, N.Y. Times, Jan. 23, 1998, at C1. Further, Microsoft has abandoned a related linkage policy under pressure from the European Commission directorate on competition law. See Andrew Ross Sorkin, Microsoft Will Revise European Contracts Amid an Investigation, N.Y. Times, Jan. 22, 1998 , at C4.

50 Jefferson Parish Hosp. Dist. No. 2 v. Hyde, 466 U.S. 2 (1984). Note that the majority and the concurrence differ on the formulations of these standards, but both engage in the same basic inquiries. 
to have at least some market power (Windows 95). Thus, the case focused on whether there were really two separate products at all. The government's claim on this point is a strong one. Microsoft evidently perceived that the browser and the operating system were, at the time of the contempt proceeding, something more than a single, "integrated" product; otherwise it would not have had to insist that they be purchased together. ${ }^{51}$ To this the Antitrust Division added evidence relating to marketing practices and the existence of separate consumer demand for each product -- the traditional (albeit backward-looking) tests for product independence. ${ }^{52}$

Unlike many tying cases, however, these facts do not constitute the sort of evidence that goes to the heart of the problem in analyzing a tie between two software products. For example, even if Internet Explorer were perfectly integrated into Windows 95, as it appears likely to be in Windows 98 absent judicial intervention, ${ }^{53}$ the installed base of Windows users who licensed their software before Internet Explorer was integrated would likely provide sufficient demand for Internet Explorer to be produced and distributed separately. In other words, much of the marketing and

${ }^{51}$ For additional anecdotal evidence along these lines, see Knowing The ABC's, supra note __.

52 In particular, the Antitrust Division contended that (i) sufficient demand exists for Windows 95 and IE to be produced and sold separately; (ii) Microsoft markets and distributes IE separately from Windows 95; (iii) Microsoft sells versions of IE designed for other platforms; (iv) Microsoft internally tracks IE sales apart from Windows 95 sales and internally perceives the markets for each to be separate; (v) Microsoft treats IE differently than it has treated mere updates or features to Windows; (vi) normal commercial practice is that browsers are distributed separately from operating systems; (vii) Windows 95 and IE may be licensed and distributed separately; and (viii) conditioning licenses of Windows 95 on licenses of IE is not necessary to the development of any integrated product. Memorandum, supra note 58. Microsoft may fairly be said not to have disputed these points as a factual matter, but to contend quite vigorously that they are "entirely beside the point" in determining whether software products are or are not "integrated." Opposition, supra note 65. As discussed below, there is merit to this contention once integration is actually achieved, but it should not be allowed to serve as a basis for demanding integration.

53 See, U.S. Sues Microsoft Over PC Browser, Wall St. J. October 21, 1997 A6; Memphis \& IE 4.0, PC Sept. 9, 1997. 
other data on which the Antitrust Division relied would likely be the same a world in which Microsoft had achieved full integration of Windows and Internet Explorer, rather than forcing a tie, and it is not at all clear that social welfare would be served by applying such data to preclude genuine integration.54

The conclusion that Internet Explorer and Windows 95 are separate products is therefore not self-evident; still less is it static. Like all software, browsers are, at bottom, binary code arranged in files, as is the operating system. To the extent Internet Explorer is a different product from Windows 95, it is because the sequences of 0's and 1's that perform "browser functions" differ from the sequences of 0's and 1's that perform "Windows 95 functions." Defining distinct software products is therefore a more delicate enterprise than is usually the case for strong complementary goods, such as cars and tires. When a truly integrated operating system (in which browser functions are inextricably interwoven) comes to market, the lines of code that perform the "browser" function will still differ from the rest of the operating system code; they will merely have been written (temporally) as part of a single version of the operating system, not as an ex post addition.

The dynamic nature of software on which Microsoft relies also suggests (when combined with the importance of market share in network markets) that social welfare will be enhanced if complementary applications are absorbed into the operating system at the rate the operating system itself advances, rather than forcibly linked as soon as the application is competitive. The Division's position may be justified, in other words, with a temporal notion of tying rather than in a traditional product-based notion.

54 Indeed, much of the debate in United States $v$. Microsoft centered on the fact that the original 1994 consent decree did not preclude subsequent integration of new products into the operating system. 
Unlike most durable goods, any distinction that can be drawn between software products will likely be ephemeral. Computer programs are regularly updated, debugged and sometimes completely rewritten as new "versions" supplant old ones. Browser code is even more dynamic than operating system code, if for no other reason than that there is less of it to write. Thus Netscape and Microsoft both moved from through numerous versions of their browsers in under three years. And one of the Division's theories of how operating system competition might be revived contemplates expansion of the browser to assume at least some of the tasks presently associated with operating systems, which implies evolution over time. Specifically, the Division articulates two ways in which this might happen. First, the browser could serve as an interface between a given operating system and an application that might not be written for that system. Second, the browser could serve as an intermediate platform for which applications could be written. Those applications would "run on" the browser, regardless of which operating system underlay the browser. ${ }^{55}$

The more the browser itself comes to resemble an operating system, of course, the more likely it is that it will introduce competition in the operating systems market. To the extent the Internet becomes a source of applications that could run on browsers (which in turn might run on a variety of simplified, stripped-down operating systems), then the applications consumers desire would themselves become platform-independent. In such a world, operating systems would

55 Readers will no doubt have discerned from the text that the Antitrust Division does not commit itself to any particular conception of the browser. In the first block quotation set forth in the text the browser is assigned the relatively humble role of playing fetch with HTML documents: it finds such documents on the Web, retrieves them, and interprets them for display on the user's computer. But elsewhere the Division assigns considerably more significance to the browser, primarily by assigning it more functions: "browsers and the technology they incorporate can serve as a platform to which applications can be written an accessed without regard to the identity of the underlying operating system." (emphasis added). 
compete on their own merits as hosts to browsers that would seek out applications residing on the Internet. If browser technology were proprietary and closed, such a world might look no different than the market at present, with the focus of network effects shifting from the operating system to the browser. If browsers operate on common, open protocols such as TCP/IP and HTML, however, true competition within the network standard could well emerge. ${ }^{56}$

This vision is plausible in significant part because the Internet already facilitates interoperation among a variety of different computers running different operating systems, from Windows to Macintosh to Unix, OS/2 and others, so long as the computers follow the TCP/IP protocol suites for Internet communications and the HTML/HTTP protocol suites for World Wide Web communications. Microsoft has been accused of attempting to leverage its operating system against these protocols, but we do not today see proprietary protocols owned by Microsoft. ${ }^{57}$

Social welfare is maximized when consumers are free to choose products that maximize their own utility and, to the extent possible, free from influence by choices that maximize the utility of other consumers, or that have done so in the past. On the other hand, network effects cannot be ignored. All consumers will benefit from widespread access to the network standard. If consumer choice is constrained by value inhering in an installed base, social welfare will be enhanced by freeing the consumer to purchase technology that differs from the installed base while preserving the benefits of interoperation with that installed base. Thus, the relevant legal regimes should seek to

\footnotetext{
56 See Lemley \& McGowan, supra note __, at __; see also infra notes ____ and accompanying text.

${ }^{57}$ Or, as Sun's Scott McNealy has put it, "Microsoft fought TCP/IP for a long time, and they gave in. They fought HTML and browsers for a long time, and they gave in. They will give in with Java, too." McNealy Defends Java Purity--Microsoft Will Cave In On Java, He Says <http://www.newspage.com/network>. Whether McNealy is right, of course, is another matter.
} 
lower the cost of extending the standard and transition among potential standards. Among other things, this goal implies a presumption in favor of facilitating interoperation with installed-base technology, ${ }^{58}$ and allowing consumers to transfer their learning investment in installed-base technology to a new, transformative technology. ${ }^{59}$ If all else can be held equal, social welfare would be better served by a platform-independent world than by a platform-dependent world.

This does not mean, however, that antitrust law can simply force platform-independence. Indeed, we suggest antitrust should not be invoked fundamentally to alter the property right granted to software by the copyright laws, which are implicitly based on the proposition that some supracompetitive return must be possible in order to encourage investment in software. Thus, Microsoft is not required either to like or to cooperate in a transition to a platform-independent world, should the market evolve in that direction. While antitrust might seek to restructure Microsoft or take away its property rights in service of this end, such as through the "essential facilities" doctrine, 60 we think such an approach is generally unwise. ${ }^{61}$

58 E.g., Sega Enters, Ltd. v. Accolade, Inc., 977 F.2d 1510 (9th Cir. 1992).

59 E.g. Lotus Development Corp. v. Borland Int'l, Inc., 49 F.3d 807 (1st Cir. 1995) aff'd by equally divided Court, 165 S.Ct. 804 (1996).

60 For an argument in favor of applying the essential facilities doctrine in this context, see Teague I. Donahey, Terminal Railroad Revisited: Using the Essential Facilities Doctrine to Ensure Accessibility to Internet Software Standards, 25 AIPLA Q.J. 277 (1997).

${ }^{61}$ One of us has argued elsewhere, see McGowan, supra note _ _, at _ , that the antitrust laws are not designed to perform rate-of-return calculations such as are implicit in the copyright laws, and therefore should not be wielded to interfere with fundamental intellectual property rights. The temptation to do so arises from the highly imperfect fit of the copyright laws with the economic characteristics of software. See Pamela Samuelson et al., A Manifesto Concerning the Legal Protection of Computer Programs, 94 Colum. L. Rev. 2308 (1994). That the same rules govern the property right in books, paintings, movies, recorded music and software suggests that some tailoring would 
More particularly, precluding Microsoft from requiring computer manufacturers to install Internet Explorer as a condition of installing Windows 95 will facilitate competition among browsers in the future and thereby, to an extent as yet undetermined, enhance social welfare. Looking at the present for a moment, if Internet Explorer is a superior browser there is presumably no need to demand that it be installed. ${ }^{62}$ If Internet Explorer is not a superior browser, demanding that it be installed will reduce social welfare.

In the future, the browser may well develop into a meta-operating system, as the Antitrust Division predicts. If that is the case, social welfare would be enhanced through maintenance of open, nonproprietary standards--such as TCP/IP and HTML--with different firms competing to offer the best browser compliant with that standard at the lowest cost. Market share might not change at all in such a world--Microsoft might "win" this competition by offering a superior product. But even if it does, we would be more confident that social welfare had been enhanced if its market position were obtained through innovation and price competition rather than the imposition of a tie.

The more difficult question concerns future integration: whether tying principles should be invoked to prohibit Microsoft from embedding browsers, or any other application for that matter, in future-generation operating systems. In part, this is properly a technological rather than a legal

be desirable. If for no other reason than the potential existence of strong network effects (to say nothing of the problem of extracting noncopyrightable ideas from the midst of copyrightable code), software protection should be more tailored than it is at present. Needless to say, however, designing the optimal intellectual property regime is far beyond the scope of the present Article. For a few thoughts on the implications of network effects in software for intellectual property, see Lemley \& McGowan, supra note __, at __.

${ }^{62}$ And indeed, even after Microsoft acceded to the trial court's order, many OEMs indicated they would continue to preinstall Internet Explorer. See supra note 
question. Antitrust has always allowed bundling where the sale of compatible products passes muster under some ill-defined measure of efficiency. ${ }^{63}$ Thus cars come with tires, batteries, and headlights, rather than menus of options from the aftermarkets that exist for each of these products. Watches come with watchbands, and left shoes come with the right, all without provoking antitrust's ire. What of code?

There is no readily apparent reason why social welfare would be enhanced by requiring any software firm to disaggregate code it actually aggregates or, in the language of the consent decree, literally integrates. There are both cost-related and consumer-related reasons to favor integration in appropriate circumstances.64 Microsoft sells many applications, such as Word, apart from Windows 95. It could sell them together, but only at a higher cost (if only in the form of opportunity cost). ${ }^{65}$ Netscape will likely continue to expand its browser to include a wider array of functions. The market presumably will react accordingly. More generally, even in the presence of operating system network effects it is reasonable to trust market forces to do a better job than a court or agency at deciding which innovations are technologically feasible and competitively desirable. The most troubling thing about the Division's case, and a plausible reading of the original order, is that it threatens to freeze technology and consumer expectations; saying, in effect, that if there are two products now, there must always be two products in the future. We would be troubled by a holding that Microsoft could never integrate its browser into its operating system, regardless of efficiency gains through integration, or changes in technological or market conditions.

${ }^{63}$ Posner, supra note 39 , at 181.

64 To cite just one example, an integrated OS/browser system might encourage some consumers to discover the Internet who would not have bothered to acquire and install a separate browser program.

${ }^{65}$ It is not as if every owner of an earlier iteration of Microsoft's operating system has purchased Windows 95; a large number will likely skip it altogether, and many who have purchased it may well skip its successor. 
From the perspective of network theory, however, it is sensible to require that integration be achieved, not forced. While the boundaries of software products are fuzzy at best, the Antitrust Division's claim may be viewed as one of temporal tying -- advancing the time at which the browser and the current version of the operating system achieve unitary status. In the context of a strong network market, that is a sensible claim to bring. Time matters more in network markets than in other markets. Given the potential importance of market share and first-mover advantages in network markets, and the potential power of an installed base, adding a temporal element to tying analysis is a sensible approach. ${ }^{66}$

In the network context, tying doctrine may enhance social welfare by using the need to maintain the installed base, and thus to write backwards-compatible iterations of code, as a means to counterbalance the power derived from the installed base. Requiring that new applications not be tied to the operating system while permitting actual integration in a new version, and while also permitting sale of the complementary application (without a tie) pending actual integration, may provide a window in which new applications can compete on price and functionality. The length of the window, likely determined by the difficulty of producing new versions of the operating system, will be a rough proxy for the strength of the installed base. The resulting equilibrium may at best reflect only a very rough approximation of the socially optimal outcome, but it may be the best that any court can do.

\footnotetext{
66 The erosion of Netscape's once-overwhelming share of the browser market highlights the need for caution in drawing broad conclusions about network theory and software in general. Netscape's diminishing market share is not what one would expect from a network market, which presumably can be locked into a proprietary standard with first-mover advantages proving decisive. The answer to this puzzle may simply be that browsers aren't really a network market. Alternatively, such erosion would be consistent with either strong network effects in the operating system, which may
} 


\section{B. The Java Wars: The Competitive Propriety Of a Proprietary Standard.}

Lying just beyond the horizon of the browser wars, but approaching fast and of potentially much greater significance, are the Java wars. These will take place on at least two fronts, on which battles are now underway. The first front is ISO, and Sun's successful effort to become the first firm to receive formal recognition to submit a proprietary product for adoption as a de jure international standard; the second front constitutes litigation between Sun and its Java licensees over the manner in which licensees treat Java and the Java trademarks. Actual litigation is now pending between Sun and Microsoft, but similar litigation could well arise in the future, particularly if Sun succeeds in its efforts to ensconce Java as an international proprietary standard.

Java gives devotees of platform-independence reason for both considerable hope and some potential concern. Java may in the future reduce, if not fully eliminate, the network benefits inuring to Microsoft by reason of its operating system installed base. If the "network" is the Java platform, operating system manufacturers would have to compete on the inherent benefits of their products (such as efficiency in RAM allocation), not on the existing base of users. Even in a platformindependent world, consumers might prefer Microsoft's products and market share might not change very much. But Microsoft's success in this new operating systems market would have to be premised on good old-fashioned competition: selling a better product at a lower price than its competitors.67 This would be an unambiguously good thing, no matter who won the competition.

have simply swamped any effects inhering in the relatively less complex browser, or with a view of TCP/IP and HTML as the standard, with the battle between Navigator and Internet Explorer reflecting intra-standard competition.

67 There is at least anecdotal evidence that Microsoft actually does quite well at both product innovation and competitive pricing when faced with competition. 
Of more concern is the possibility that if Java fulfills its promises, we might find that we have simply traded Microsoft for Sun: that once Java becomes a standard, Sun will use its proprietary nature to close the standard and act as a monopolist with durable power. To be fair, this currently seems unlikely. Sun has reiterated in many different fora its commitment to platformindependent computing. It has, nevertheless, insisted on retaining intellectual property rights in Java, its proposed vehicle for platform-independence. While Sun might or might not be a more benevolent monopolist than Microsoft, the real promise of Java is based on the standard remaining open, and offering us the joint benefits of network effects and intrastandard competition.

To begin: what, precisely, is Java? As described in its amended complaint against Microsoft:

Sun Microsystems is the developer and licensor of the JAVA ${ }^{\mathrm{TM}}$ Technology, which comprises a standardized application programming environment that affords software developers the opportunity to create and distribute a single version of programming code that is capable of operating on many different, otherwise incompatible systems platforms and browsers. ${ }^{6}$

A "standardized application programming environment" sounds to many like an operating system: a good for which applications may be written and that coordinates the computer's functions. The difference is in the meta-operating system characteristic Sun ascribes to Java technology -- it is billed as the operating system whose job it is to allow any operating system to function with applications written for any other operating system (or possibly without any system other than Java in mind), so long as both the operating system and the application are themselves compatible with Java. Java

${ }^{68}$ First Amended Complaint of Sun Microsystems, Inc. $\$ 2$ (available at http://java.sun.com/aboutJava/index.html>. For more detail on Java and its various aspects, see Bruce Simpson et al., Making Sense of Java (1996). 
may be, in other words, the Antitrust Division's view of a platform-independent competitive horizon coming to life.69

According to Sun, Java has achieved rapid, widespread, and growing acceptance in the software community. Its complaint against Microsoft cites reports that: 750,000 programmers will be writing Java code by the end of 1997; over 1 million users downloaded Sun's Java Developer's Kit from the Internet between February and October, 1997; over 200 universities have established courses including Java; over 800 books have been published on Java; and over 100,000 programmers from 140 countries subscribe to Sun's "Java Developer Connection" Internet service. ${ }^{70}$ In addition, Sun has licensed Java to approximately 120 firms, including Netscape, Oracle, IBM, and, of course, Microsoft. ${ }^{71}$ Companies are even designing hardware products optimized for Java.72

Sun is backed to a greater or lesser extent in this endeavor by a coalition of firms that has formed behind Sun's efforts to achieve recognition of the Java platform as an international standard while retaining certain intellectual property rights. Dubbed by some the "ABM" (Anything But Microsoft) Coalition, ${ }^{73}$ IBM, Netscape, Novell, Oracle, and Sun have reportedly banded together in what is for all practical purposes a joint venture aimed at achieving platform-independent computing

69 Some complain that true platform independence is impossible, or even undesirable. See, e.g., Steve G. Steinberg, Schumpeter's Lesson, Wired, Jan. 1998, at 80, 84. We don't have the background to evaluate Java on its technical merits; the most we can do is investigate the potential economics of a platform-independent world.

${ }^{70}$ Amended Complaint, supra note 81, \443.

71 Sun Suit Says Microsoft Disrupts Java, Wall Street Journal, October 8, 1997 A3; Sun Microsystems' Press Teleconference <http://java.sun.com/pr/1997/Nov/pr971117.tran.html>.

72 See Frederick Rose, Rockwell Is Set to Unveil Chip Created for Java, Wall St. J., Sept. 22, 1997, at B6.

73 See William F. Zachmann, Sun's ISO Java Victory <http://www.browserwars.com/articles/zachmann/wz971117.asp>. 
using the Internet as their cornerstone and Java as a universal platform interfacing among the divergent standards on the Internet. ${ }^{74}$

Antitrust often encounters firms taking steps to further their interests in trade or standardsetting organizations. As with litigation generally, such encounters are usually described in retrospect, after a firm has suffered a harm it believes warrants redress in the courts. ${ }^{75}$ Sun's Java technology, and the access afforded by the Internet, offers a rare opportunity to examine the behavior of firms competing through a standard-setting process in essentially real time. For that reason, and because of the potential for the Java technology fundamentally to alter the current paradigm of platform-dependent competition, we examine the ISO's Java evaluation in some detail here.

On March 14, 1997 Sun submitted to Joint Technical Committee 1 ("JTC-1") of the ISO and the International Electrotechnical Commission (IEC) a request for recognition as a Submitter of

${ }^{74}$ See, e.g., Elizabeth Corcoran, Five Companies Link Up to Take Microsoft Down, Wash. Post, Nov. 16, 1997, at A1; Rivals Target Microsoft, S.F. Examiner, November 16, 1997, at A1. Combining understatement with admirable candor, a Netscape representative described the venture as follows:

There's a very strong incentive for us to push as hard and fast as possible toward a world where operating systems are commoditized, chips are commoditized and the Net becomes the platform.... We all see an opportunity to make tremendous amounts of money as that world unfolds--as opposed to [a] world where everything is Microsoft and Intel Corp. That's the big issue.

Id. (quoting Mark Andreesen, Chief Technology Officer for Netscape).

75 For a paradigmatic example, see Allied Tube \& Conduit Corp. v. Indian Head, Inc., 486 U.S. 492 (1988) (describing alleged packing of meeting of members of the National Fire Protection Association to defeat measure approving of polyvinyl conduit, a potential substitute for stainless steel conduit manufactured by many NFPA member firms). 
Publicly Available Specifications ("PAS") for Java. ${ }^{76}$ In its application, ${ }^{77}$ Sun sought recognition for the Java "platform," which as of the date of Sun's submission, March 14, 1997, consisted of "the Java language, the class file format, the byte codes recognized by the Java Virtual Machine, and the Java APIs."78 As of March, 1997 Sun considered the first three components of the platform to be "most mature" and "the likely first candidates for submission" as a standard, while the APIs were in varying states of maturity. ${ }^{79}$

Sun's PAS application reflects many things, not the least of which is the recognition by ISO and IEC members, both in their adoption of the PAS process and their approval of Sun as a PAS submitter, that information technology moves quite rapidly (faster, in any event, than the consensus-based standardization process has moved in the past) and that proprietary products may become de facto standards in information technology markets. Recognition of these facts led JTC-1 to adopt a procedure for the "Transposition of Publicly Available Specifications into International Standards. ${ }^{180}$ The PAS process is designed to achieve three goals: keep standardization current in

${ }^{76}$ Established in 1906, IEC was the pioneer organization in international standardization. ISO works closely with IEC on matters of electrotechnical standardization. A 1976 agreement between the two organizations allocates responsibility for electrical and electronic engineering to IEC; all other subject areas fall within ISO's jurisdiction. <http://www.iso.ch/infoe/intro.html>. As ISO is a more familiar name (at least among lawyers) with respect to standardization, we refer to it in the text.

${ }^{77}$ See <http://java.sun.com/aboutJava/standardization/index.html>.

${ }^{78} I d$. API stands for application programming interface.

${ }^{79}$ Sun's license and its development kit include the Java APIs, as well as the Java Compiler, which translates the (human-readable) source code written in the Java programming language into binary code, which are stored in the class files. The kit also includes the Java Runtime Interpreter, which interprets compiled Java code "and causes the host's platform operating system or browser to execute those instructions as if they had been written for the 'native' programming environment of the systems platform or browser." Amended Complaint, supra note 81, $\mathbb{I}[26(\mathrm{c})$.

80 See Transposition of Publicly Available Specifications (PAS) into International Standards (DRAFT)--A Management Guide, <www.iso.ch/dire/jtc1/pas/html>. 
information markets, with a target of transposing suitable text to standards in 12 months; encourage "the contribution to international standardization of proven specifications which may be considered de facto standards by virtue of their wide market success;" and provide ISO with technical expertise they may not have on their own but which may be necessary for standardization in certain

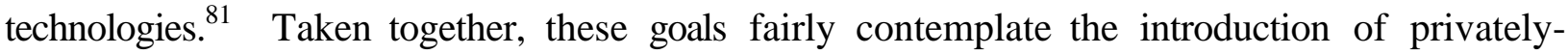
developed, privately-owned products as candidates for transformation into international standards. ${ }^{82}$

In the initial round of voting on Sun's application, 3 member nations voted to approve Sun as a PAS Submitter, 5 voted approval with comments, and 15 voted disapproval with comments which, under JTC-1 rules, constituted conditional approval subject to Sun's response to the comments. As discussed in greater detail below, the comments adduced from this round of voting centered on two topics of interest to competition policy: whether a single firm should be allowed to submit proprietary technology under the PAS procedure and whether such a firm should be permitted to retain intellectual property rights in the proposed standard. ${ }^{83}$ During this process, Sun

\footnotetext{
${ }^{81} I d$.

82 See Management Guide, supra note 91. Section 6 of the Management Guide states that "[t]here are no formal conditions or restrictions as to what form the organization should take." Section 3.3 of the Annex "A" to the Management Guide calls for "organizations" seeking PAS recognition to respond to a number of queries regarding intellectual property rights held by the organization that relate to the proposed standard.

83 These questions were also raised by the ad hoc committee formed by the American organization voting on the proposal, the United States JTC-1 Technical Advisory Group ("U.S. TAG"). See <http://www.jtc1tag.org/jt97264r.htm> (minutes of June 4-6, 1997 meeting).
} 
and Microsoft exchanged two sets of letters to the United States Technical Advisory Group ("U.S. TAG") to JTC-1 addressing such issues. ${ }^{84}$

Sun submitted a detailed response to the comments from the first round of voting, in which it articulated its vision of the manner in which a PAS Submitter could retain intellectual property rights in an international standard. ${ }^{85}$ A second round of voting then commenced, resulting in approval of Sun as a PAS submitter in November, 1997. ${ }^{86}$ Sun will now proceed in its efforts to have Java adopted as an international standard. That process in turn entails Sun's submission of the

84 Sun's responses may be found at <http://java.sun.com/aboutJava/standardization/april30response.html> and $<$ http://java.sun.com/aboutJava/standardization/may20response.html>. Microsoft submitted a detailed analysis of Sun's response to the overall comments from the first round vote (<http://jtc1tag.org/jt970457.htm>).

85 See <http://java.sun.com/aboutJava/standardization/response1.html>.

${ }^{86}$ Each ISO member nation receives one vote. The vote in favor of recognizing Java as a PAS was 20-2, with Italy and Switzerland abstaining. The United States and China voted against recognition. U.S. TAG voted against recognition, with comments, in June, 1997. See, supra note 94 (minutes of June 4-6, 1997 meeting). The minutes of the June 4-6 meeting reflect substantial discussion and multiple votes on issues relating to the application. Id. During U.S. TAG's October 28-29 meeting, it considered whether to change its vote to approve Sun's application, in light of Sun's responses to comments accompanying the first ballot, comments made by U.S. TAG members (the most extensive of which were provided by Microsoft), and comments from non-members. (Devotees of conspiracy theories will no doubt find much grist for various mills in the location of the meeting: Microsoft Corporation, Redmond Washington. <www.jtc1tag.org/oct97>.) According to Sun, a majority of U.S. TAG voted in favor of recognition but fell two votes short of the 2/3 majority needed to override the prior vote. Sun attributed its failure to prevail within U.S. TAG to "a situation where a small number of companies in the U.S., one of them software and three of them hardware, simply lobbied very hard -- including putting pressure on some of their partners -- to just barely escape a 2/3rds majority 'yes' versus the simple majority 'yes' that the U.S. did provide." <http://java.sun.com/pr/1997/nov/pr971117.tran.html> (comments of Alan Baratz, President of Sun's JavaSoft division). 
aspects of Java technology for which it seeks recognition as a standard, together with an "Explanatory Report" generated by Sun in support of its submission. ${ }^{87}$

The intellectual property issues that provoked comments during the first round of voting on Sun's PAS application will likely be the subject of a fair amount of both "advice" and "negotiation";88 it is perhaps not too cynical to envision some amount of lobbying as well. ${ }^{89}$ These issues are in any event of broad importance to both intellectual property and competition policy, and they bear close study. Before analyzing those issues, however, it is useful briefly to consider a question that should not be on the table during the forthcoming balloting but that was raised both within U.S. TAG and by other countries during the first round of balloting: whether a single firm should be allowed to submit proprietary technology for adoption as a standard.

It is, to say the least, very odd to see Microsoft and China allied on a question of intellectual property rights. Sun's PAS application, however, produced such an alignment. ${ }^{90}$ Microsoft took the

87 Management Guide, supra note 91 (Section Six).

88 See id. (JTC-1 to provide "advice" to PAS Submitters); <http://java.sun.com/pr/1997/nov/pr971117.tran.html> (comments of Jim Mitchell, Vice President for technology and architecture of Sun's JavaSoft Division) (characterizing the process as a "negotiation" with JTC-1).

89 According to one report, Sun's approval as a PAS Submitter is attributable to "an extremely determined and very effective lobbying effort on behalf of Sun's proposal by members of the ABM coalition generally and by IBM in particular. According to reports from around the world, IBM essentially pulled out all the stops in a full-court press to lobby reluctant national standards bodies to vote in Sun's favor. The scope and intensity of this effort shows how deadly serious IBM is about using Java as a weapon against Microsoft." Zachmann, Sun's ISO Java Victory, supra note 86 .

90 In casting its first-round vote, China commented that it "believes that standards shall be developed in an open and consensus building process consistent with ISO principles, in a non-profit unbiased standard organization. An individual shall not control such a process." China further noted that it was "disturbed by the consequence possibly incurred by the ownership of the Trademark, Distribution rights and its further maintenance right of an international 
position that no single firm should be accorded the status of PAS Submitter, in part because any single firm with a proprietary product would be driven by market forces rather than the need to achieve consensus through cooperation that had been the paradigm for standardization efforts in the past. ${ }^{91}$ These concerns are reflected to some degree in Microsoft's comments before the secondround voting, in which Microsoft urged that U.S. TAG adhere to its initial negative vote in part because, under Sun's proposal,

Sun will continue to set the rules for evolution and branding of Java and asks ISO to endorse the Sun Java product and distribute Sun-authored specifications. Sun plans to maintain control over all substantive changes and enhancements to the Java technology. At the same time, Sun seeks to gain ISO as an endorser, if not advertiser, of Sun's products via the use of an 'open' specification name that explicitly references Sun's proprietary implementation. ${ }^{92}$

These concerns led Microsoft to conclude that "Sun should not be given the benefit of ISO standardization of its technologies while controlling them as proprietary products that compete with vendors like Microsoft and others." 93

These are not trivial concerns, though Sun would likely question the sincerity with which they were raised. ${ }^{94}$ There are really two separate issues here, however. The first is whether a single

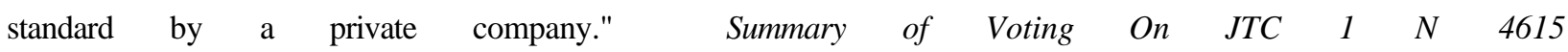
<http://java.sun.com/aboutJava/standardization/jln4833.html>.

91 See <http://java.sun.com/aboutJava/standardization/april30response.html> (characterizing Microsoft's argument).

$92<$ http://www.jtc1tag.org/jt970457.htm>.

93 Id.

94 See, e.g., <http://java.sun.com/pr/1997/sept/qa.html> (press conference accompanying Sun's submission of its response to JTC-1 comments) ("anything Microsoft says, anything Microsoft does, with respect to Java needs to be understood in that context, a monopoly that is trying to protect its monopolistic practices") (Comments of Alan
} 
firm should be allowed to submit a proprietary product for consideration as a standard; the second is the manner in which the Submitter's intellectual property rights are treated during the standardization process. The question whether a single firm should be recognized as a PAS Submitter should be answered with an eye to the ISO's recognition that information technology markets tend to adopt de facto standards and to do so very quickly. Information is most useful when it can be shared, and sharing implies interoperability. If a given market, such as the operating systems market, exhibits strong network effects, then tipping to a de facto standard is likely. This is true even if the de facto standard is a proprietary good licensed only by one firm, such as Windows.

If information technology markets exhibit strong network effects as an inherent part of their competitive model, and are therefore likely to tip to a proprietary standard regardless of the actions of standard-setting organizations, there is no readily apparent reason why a single firm should not be permitted to submit proprietary technology for adoption as an international standard. There seems relatively little risk that social welfare would be diminished in such a case, and the process of standardization could quite possibly enhance social welfare by encouraging the opening of what would otherwise be a closed standard. ${ }^{95}$ The objections that allowing a single firm to submit

Baratz, President of Sun's JavaSoft division); Laurence Zuckerman, Sun Microsystems Rejects Suggestions It Give Up Java, N.Y. Times, Sept. 23, 1997, at C7.

${ }^{95}$ The comments at the June, 1997 U.S. TAG meeting that opposed recognizing a single firm as a PAS submitter focused on the deleterious effect of such recognition on the traditional standardization process. Members (unidentified in the minutes) argued that "[c]onsensus standards development has no future if single companies are permitted to originate standards"; "[p]ermitting single companies as PAS submitters undermines the value of international standards"; and single-firm recognition "would set a precedent that consensus is not a necessary ingredient in the development of international standards." <http://www.jtc1tag.org/jt97264r.htm>. These points are entitled to some weight from the perspective of organizational concerns within ISO. They do not establish, however, that standardization will not take place if ISO refrains from considering single-firm Submitters and/or their proprietary standards. The choice to do so reflects a recognition by ISO that any other course could leave ISO on the sidelines of market standardization contests. To the extent the ISO process may enhance the quality of deliberation directed toward 
proprietary technology would be inconsistent with a consensus-building model may be true from a organizational viewpoint, but de facto standardization through competition in the market will not necessarily achieve greater consensus and, given the history of various standards competitions within the market, is more likely to resemble a "winner take all process" than a consensus-building process. The ISO PAS process reflects this reality and is right to do so; ignoring the economic characteristics of the relevant marketplace is a prescription for irrelevance.

Of course, recognition of a firm as a PAS Submitter might have independent competitive significance in the market. ${ }^{96}$ Microsoft's contention that Sun sought to transform the ISO into "an endorser, if not advertiser, of Sun's products" has some resonance in a network market, in which consumer expectations about which product will become the industry standard are very important. Though the approval of ISO likely would not be decisive in the face of market forces of any strength, recognition of Java as an international standard could carry significant psychological weight

selection of a standard, the PAS process may enhance social welfare, a possibility that tends to outweigh the objections to single-firm recognition.

Further, it is worth noting that most standard-setting organizations permit private, proprietary specifications to be submitted as standards. At most, they require disclosure of the intellectual property rights at issue, and compulsory licensing on reasonable terms once it becomes a standard. So it would be wrong to conclude that the ISO had done anything out of the mainstream by allowing Sun to submit Java as a standard.

${ }^{96}$ There will be some effect on the extent of the market for Java if it is approved as a standard. In commenting on ISO approval of Sun as a PAS Submitter, Sun executives ranked the support recognition reflected for its vision of platformindependence as most important from an economic point of view, characterizing such recognition as having "enormous value to Sun and enormous value to almost every company within the industry and end users as well." Sun attributed secondary significance to "the notion that there are a number of government institutions or universities or other entities that are uncomfortable buying a product unless it's based on ISO-standard technology." <http://java.sun.com/pr/1997/nov/pr971117.tran.html>. 
with programmers and others whose decisions with respect to writing applications may help determine the competition's outcome. Microsoft is thus right to be worried about the competitive implications of Sun's recognition as a PAS Submitter: formal status may well benefit Sun at some cost to Microsoft. It does not follow, however, that recognition of Sun as a PAS submitter places social welfare at risk. Microsoft is the recognized vendor of a proprietary de facto standard as it is. $^{97}$

The important question, then, is how Sun's intellectual property rights will be treated during the standardization process. We focus our attention on the general intellectual property rights involved and the implications of differing configurations of those rights for competition policy. The general danger of allowing a private party to own intellectual property rights in an open standard is that the private party may at some point attempt to close the standard, either by licensing it on discriminatory terms or by setting an unreasonable price for continued access. If the standard has been widely adopted in a network market, this form of "intellectual property ambush" can impose a significant cost on users of the standard.98

97 Both Microsoft and Sun compare Java with Windows. In it submission to U.S. TAG before the second round of voting, Microsoft stated that it "believes that for Java's own welfare it must be placed firmly in either the commercial, market-driven standards domain (similar to Microsoft Windows) or into an official standards regime with its guarantees of fairness and due process. To attempt to mix the two is seductive but a disservice to both." <http://www.jtc1tag.org/jt970457.htm>. For its part, Sun states that "[w]e'll consider putting the Java trademarks in the public domain when Microsoft relinquishes control over the Windows specification and trademark." <http://java.sun.com/pr/1997/sept/transcript2.html> (Comments of Jim Mitchell, Sun's Vice President of Technology and Architecture> -- an eventuality Sun can reasonably assume is remote.

98 For discussion of allegations of this sort made in the past against Dell and Unisys, see Lemley, supra note , at 
Sun has sought to alleviate these concerns to some extent. In its response to the first round voting, Sun clarified three issues in particular. First, Sun stated that its policies with respect to patents in the Java platform were more liberal than required by ISO policy, and stated its willingness to follow ISO policy or extend its current policy. ${ }^{99}$ Second, Sun stated that it would grant ISO "all necessary rights to print and sell copies of the International Standard without payment of copyright fees or royalties." ${ }^{100}$ This presumably resolved the copyright issue, though it is worth noting that "rights to print and sell copies of the International Standard" may or may not include copies of the source code for all of the important pieces of Java.

That left trademarks. Though software code itself is protected primarily by patent and copyright, not trademark, it is with respect to trademark rights that matters have become more complicated. Sun's response stated unequivocally that, while it would permit use of the Java mark to describe products that utilized the Java specifications adopted by the ISO, it would retain the rights to the Java mark itself, and reserve the right to deny a license to firms that do not satisfy its licensing criteria:

We expect to continue to own all of our trademark logos and names and would not expect to transfer the rights associated with them to ISO.

Java(tm) is a trademark of Sun Microsystems, Inc., that describes the name of a product--a brand--not the name of the set of specifications for this ubiquitous computing platform. Sun Microsystems, Inc., invented and developed the Java(tm)

$99<$ http://java.sun.com/aboutJava/standardization/response1.html>. According to the response, Sun's patent policy is to automatically grant[] to users of the Java(tm) platform specifications a fully-paid, worldwide, limited license in perpetuity that allows them to create and distribute their own implementations of our specifications without paying any fees or royalties to Sun for the use of our patents that are necessary $100 I d$ to practice the specifications. 
product. To further the use of that product, Sun extracted the specifications and supplied those specifications to its direct licensees, and then to the general computing community, with licenses for use and implementation.

Sun is not giving its products to ISO. We want to standardize the specifications that underlie those products through ISO. ${ }^{101}$

Thus, Sun concluded, while it was willing "to permit ISO to use the term 'Java(tm) Platform' in the name of the International Standard," ${ }^{102}$ it was not willing to give its Java mark to ISO in connection with adoption of Java as a standard. Sun's response instead explicitly proposed a market in which firms utilized the ISO standard to "build completely separate, conforming implementations of" the contemplated ISO specifications "with no commercial relationship to Sun." Under this approach, such implementations would be marketed under a different brand, owned by the firm producing the implementation. Firms would thus have two choices: if they wished merely to adhere to the ISO standard, they could label their products "ISOxxxx conformant." Alternatively, they could enter into a licensing agreement with Sun and use "Java" to describe their products. ${ }^{103}$

In practice, there is a third alternative dictated by trademark law: a firm could use the term "Java" or "Java-compatible" in order accurately to describe its relationship to Java.104 Sun's

\footnotetext{
${ }^{101}$ <http://java.sun.com/aboutJava/standardization/response1.html>.

${ }^{102}$ Sun's example of the name for the standard was "ISO.xxxxxx, The ISO Specification for the Java(tm) Platform." Id.

${ }^{103} I d$.

104 Courts will, however, strictly monitor the use of the word "compatible." See, e.g., Creative Labs. v. Cyrix Corp., 42 U.S.P.Q.2d 1872 (N.D. Cal. 1997); Princeton Graphics Operating L.P. v. NEC Home Electronics, 732 F. Supp. 1258 (S.D.N.Y. 1990).
} 
licensing guidelines permit licensees to advertise their products as "XYZ for Java(tm)," ${ }^{105}$ while simultaneously recognizing under the rubric of trademark "fair use"106 that firms whose products incorporate the Java specifications may mention the Java mark in advertising so long as the reference unambiguously refers to Sun's products and does no more than accurately describe a characteristic of the firm's product. ${ }^{107}$ In other words, at least in the United States, trademark principles might well permit the use of the Java name by firms other than Sun to indicate that their applications worked with Java, so long as this statement was in fact true. ${ }^{108}$ This does not necessarily weigh against Sun's proposal, but it does mean that the proposal is not a large sacrifice of Sun's trademark rights.

From a social welfare perspective, Sun's suggested approach to standardization in the presence of intellectual property rights is not as simple as it may appear at first blush. The difference Sun seeks to draw between the Java specifications and the Java product is far from clear. The implications for competition policy become somewhat clearer when the question of conformance to the proposed standard is introduced. As the foregoing quotation indicates, under Sun's approach conformance to the ISO standard, and thus the right to designate a product "ISOxxxx" compatible, would be voluntary. Use of the Java mark might require a firm to deal with

\footnotetext{
$105<$ http://java.sun.com/aboutJava/standardization/annexes.html\#AnnexD> (Under Section 3 of Sun's Java Trademark Guidelines, however, licensees may not advertise products in a "Java for XYZ" format).

106 See Zatarain's, Inc. v. Oak Grove Smokehouse, Inc., 698 F.2d 786 (5th Cir. 1983) for a discussion of trademark's fair use doctrine, which differs significantly from the doctrine of the same name in copyright law.

107 Id., Section Five ("Fair Use of the Java Mark: Taglines").

108 See, e.g., The New Kids On the Block v. News America Publishing, Inc., 971 F.2d 302 (9th Cir. 1992) (use of a mark to refer to the mark's owner while accurately describing attribute of service offered was "nominative fair use" of trademark); Robert P. Merges et al., Intellectual Property in the New Technological Age 1018-1020 (1st ed. 1997).
} 
Sun, which Sun promised to do on "a fair and nondiscriminatory basis on reasonable terms." 109 At the least, using the Java mark without permission would require strict adherence to the law of "nontrademark use."

In this context, the trademark action Sun recently filed against Microsoft presents certain issues worthy of further consideration. The fundamental issue in the case concerns Microsoft's alleged alteration of certain aspects of the Java code. Microsoft has claimed it altered the Java specifications to "optimize" Java's performance with Windows. Sun contends Microsoft is attempting to co-opt the Java platform by designing a separate, proprietary "version" of Java that runs on Windows, but not on competing operating systems.110 Sun's concern is that a Windowsspecific version of Java could undermine the potential transition to platform-independent competition. This dispute raises some fundamental antitrust and intellectual property issues. If Microsoft can alter the Java code so that it is not in fact platform-independent, it will have shortcircuited the promise of Java. Indeed, it might not even need to do that much -- as long as Microsoft's version of Java works better with Windows than others, users may gravitate towards that version, and hence remain locked in to the Windows operating system. If Java were truly an open platform, owned by no one, it is hard to see how Sun could prevent this. Ironically, Sun's reservation of its intellectual property rights in Java now gives it an opportunity to prevent

109 Sun agrees that conformance to International Standards is based on voluntary decisions by suppliers. In particular, implementors of the specifications will be able to claim that their products are 'ISOxxxx conformant' without passing any formal test by Sun ar any certification agency.

Those who wish to claim that their products are explicitly conformant to or compatible with Sun's Java(tm) product or platform, however, may do so by entering into a licensing agreement with Sun on a fair and non-discriminatory basis on reasonable terms, as many companies do.

<http://java.sun.com/aboutJava/standardization/response1.html> (Section 2.4).

110 See Lee Gomes, Sun, Microsoft Reveal Contract Key to Java Rift, Wall St. J., Oct. 16, 1997 , at B6. 
unauthorized alteration of the standard. From a social welfare perspective, if Sun would keep Java open, and Microsoft would effectively close it, there are good policy reasons to back Sun in this suit.111

Sun has chosen to fight this battle under trademark law.112 Sun's amended complaint against Microsoft states with respect to the Java marks that

$[\mathrm{u}]$ nder license from Sun, a systems manufacturer or browser developer . . . is licensed to distribute products including the $\mathrm{JAVA}^{\mathrm{TM}}$ Technology, provided the product has passed Sun's Test Suites, is otherwise fully compatible, and displays the JAVA compatible logo. The JAVA Compatible logo symbolizes that the product bearing the logo has successfully passed Sun's Test Suites and otherwise complies with Sun's set of JAVA specifications and JAVA APIs, such that programs written for the JAVA ${ }^{\mathrm{TM}}$ programming environment will run successfully on that implementation and on any other JAVA Compatible implementation. ${ }^{113}$

Consistent with this concept, Sun alleges its trademark license

111 We do not intend to express any opinion on the merits of the trademark law claim, or on the substance of the license agreement between the parties. They are dependent on facts we simply don't have.

112 It is not clear why trademark and not copyright is the appropriate tool here. Copyright law generally gives copyright owners broad rights to prevent the creation of unauthorized "derivative works," see 17 U.S.C. § 106(2); Mark A. Lemley, The Economics of Improvement in Intellectual Property Law, 75 Tex. L. Rev. 989 (1997); that seems to be precisely what Microsoft has done here. Perhaps Sun concluded that the terms of its license agreement with Microsoft permitted modifications of the sort Microsoft had made. See David Bank, Microsoft Replies to U.S. Complaint, Sues Sun Microsystems in Java Dispute, Wall St. J., Oct. 28, 1997, at B6 (citing Microsoft's argument that "during negotiations over the licensing agreement Sun gave Microsoft the right to adapt and alter Java in return for a $\$ 3.5$ million fee").

113 Amended Complaint, Q[40 (emphasis added). 
authorizes Sun to inspect and test any products of Microsoft distributed in association with the JAVA Compatible logo to ensure that they meet the compatibility requirements of the [Technology License and Development] Agreement, and obligates Defendant Microsoft to promptly make any modifications to such product necessary to meet the conditions for displaying of the JAVA Compatible logo. ${ }^{114}$

What these allegations imply for ISO purposes is not entirely clear. Section 2.2.3 of Sun's response, pertaining to trademarks, is consistent with the allegations, stating that the Java marks "are used to represent that a given implementation of Java meets the strict compatibility and interoperability criteria inherent in the Java(tm) platform specifications." Section 2.4 of Sun's response, however, states that "the conformance statement in the Java(tm) platform specifications requires complete and compatible implementations of the current version of the specifications without subsetting or supersetting" and that these conformance requirements will be part of the technical standard Sun submits to ISO. ${ }^{115}$

If the performance statement in the platform specification to be submitted to ISO is the equivalent of the requirements imposed on Sun's trademark licensees, then the Java mark will designate only that Sun has reserved the right to approve products bearing the mark by running its own test suites. The Java mark would not, by hypothesis, designate a uniquely conformant level of technology. ${ }^{116}$ The "ISOxxxx conformant" designation Sun suggests would differ only in that products bearing that mark would not be subject to testing by Sun; use of that mark would be a

\footnotetext{
114 Id. $\$ 63$.

115 <http://java.sun.com/aboutJava/standardization/response1.html>.

116 At least not within a given iteration of the platform technology. If the branded technology evolved faster than the standard, or if the branded technology were not backwards-compatible, then a substantive difference between Java and "ISOxxxx conformant" technology would of course exist.
} 
declaration by the producer that it had complied with the specifications but would not imply agreement by Sun with that declaration. The Java mark could, however, carry some weight, and perhaps determinative weight in a competition among Java-compatible applications, as an assurance that the product at hand would in fact work with the most current Java technology.

In network markets consumer expectations may be the key to competition. If, as Sun has alleged, the Java trademarks uniquely convey to the market that a product adheres strictly to the Java specifications, then firms competing in a Java-based world might feel substantial pressure to agree to Sun's conditions for issuing a trademark license. ${ }^{117}$ Sun would, in other words, serve both as a source of competitive products and as a supervisor of competition. It is little wonder that Microsoft's comments to U.S. TAG before the second round of voting accused Sun of being a fox seeking international authorization to guard the henhouse. ${ }^{118}$ On the other hand, if Microsoft can

117 As George Paolini, Director of Corporate Marketing for Sun's JavaSoft division, put it in commenting at a teleconference held after submission of Sun's response, "[a] major distinction between Unix and Java, technology aside, is the power of the Java brand. We have been very effective in using the brand to essentially keep the industry on one platform, one Java platform. We have done this by using the brand to certify and allow the use of the brand in various substantiations (sic) for those who comply. If you don't comply, you will lose the right to use the brand. So far that has worked extremely well." <http://java.sun.com/pr/1997/sept/qa.html>.

${ }^{118}$ Microsoft's comments to U.S. TAG before the second round of voting stated that "[b]y using its trademarks to control compliance with its proprietary implementation of Java, Sun would effectively control compliance with the proposed International Standard for Java while competing in the marketplace with other vendors seeking to conform to the standard. To allow a competitor to have this much control undermines the credibility of the standard." <http://www.jtc1tag.org/jt970457.htm>. 
create its own, closed version of Java, Microsoft may well have substantial power to redirect consumers from Sun's platform-independent Java to its own, platform-dependent version.119

The situation becomes more complex as the standard begins to evolve. Many of the round one comments focused on the manner in which the Java standard would be maintained if it were adopted by ISO. Sun's response was to propose that it continue its own "open and inclusive" development process, and that a Working Group within JTC-1 be created to address "all aspects of maintenance including: handling defect reports, writing draft technical corrigenda, writing draft amendments, and carrying out the five-year periodic review of the International Standard."120 Working group participation in new versions of the Java specifications is noticeably absent from this list, and Sun has made it fairly clear that it considers evolution of the (branded) standard to be within its ultimate control, reserving evolution of the standard for new submissions by Sun to JTC1.121

119 Microsoft could, of course, choose to compete within the Java standard by modifying Windows to run Java more efficiently than competing operating systems do. Such intra-standard competition would likely enhance social welfare.

$120<\mathrm{http} / /$ java.sun.com/aboutJava/standardization/response1.html> (Section 2.1).

121 As Sun's Jim Mitchell explained on the teleconference accompanying Sun's submission of its response, "[m]aintenance is fixing these bugs and everything, and there is a process in JTC 1 to go through that and put even those things up for voting and comment. But if Java changes in some substantial way what we would expect to do is a new submission of the Java platform specs." <http://java.sun.com/pr/1997/sept/qa.html> (emphasis added). It should be noted that Sun considers its process for evaluating changes to the branded Java specification to be more open than the normal JTC-1 process. In Sun's view, maintaining its ability to rely on sources--such as developers or endusers--who suggest changes outside the ISO process enhances its ability to maintain Java as a true industry standard. Sun contends quite strongly that

the primary value proposition of Java is Write Once, Run Anywhere. When the entire computer industry shifts it in order to keep write one run anywhere we have to get consensus around 
It is at least possible, therefore, that Sun could adopt new branded standards before JTC-1 had agreed to the parallel "ISOxxxx conformant" standard, thereby creating a divergence between the branded technology and the ISO standard. Recalling again that network theory predicts rapid adoption of de facto standards, if competitive reality compelled firms to use the Java marks, the branded standard might well remain the "true" standard in the marketplace. ISO might bless each version as adopted, and JTC-1 members might have input into evolution of the branded standard, but if JTC-1 sought changes to the "ISOxxxx conformant" standard that were not embodied in the branded standard, such proposals would likely not matter very much. The Java standard would effectively be a private de facto standard, not an ISO-determined one.

Should this be of concern? If Sun's process of evolution remains as open as it is now advertised to be, there ought to be no harm to social welfare. Whether the standard is set by JTC-1 or by Sun itself, so long as it is open, applications programmers, OS programmers, and consumers will all benefit from the interoperability it confers.122 If, however, ISO adopts Java as a standard and thereby helps Sun in wresting the marketplace away from Windows, and Sun thereafter is more

changes. That's why we run as open a process as we do ... [w]e can no more veto or do something with just one company--if we do that we have killed that right to run anywhere, so our process is open because it has to be. That's in enlightened self-interest. It's not altruism.

Id. This statement is revealing in three respects. First, it does not deny that Sun has the authority to pass judgment on changes to branded Java technology, and that it does not propose to surrender that right as part of the ISO process; second, it characterizes the value of Java as being, in game-theoretic terms, a hostage effectively precluding Sun from exercising this right in an arbitrary manner; third, it characterizes the "Write Once, Run Anywhere" attribute of Java as a "right" inhering (presumably) to the benefit of those who comply with branded specifications. Treating this right as legally enforceable might ameliorate some concerns that Sun's dual position as competitor and monitor might otherwise raise, though the right need not necessarily be embodied in antitrust law.

122 The actual substance of the standard may vary depending on who sets it, of course. But as noted above, it is not clear that we should prefer to have our computer programs designed by a bureaucratic group rather than a private company. See Lemley, supra note for a discussion of some of the problems with group-developed standards. 
selective about the changes it is willing to make, or who it will license Java to, social welfare might be diminished. It is in this scenario that Sun might replace Microsoft as the owner of a closed, proprietary standard.

From the perspective of competition policy, this risk is difficult to evaluate in the abstract and even harder to hedge. Sun is correct to contend that it does not have limitless ability to alter the Java standard if it wishes to increase market share, particularly not while Windows enjoys the type of market share it has now. So it is possible that the marketplace itself will put at least a temporary constraint on Sun's ability to close its standard. It may also be the case that Sun's commitment to open systems is genuine, and will survive Java's adoption as a standard regardless of the financial benefits to Sun of closing the standard. But we would be more comfortable if firms making investments in reliance on what Sun has characterized as a "right" to platform-independence inherent in the branded Java specifications had some legal means to enforce this right to the extent of their reliance.

Enforcement might take an array of forms. One possibility is to imply a covenant under contract law. Draft UCC2B Section 402(a)(1), which requires software performance to conform to "affirmation[s] of fact" by a licensor in any manner, "including in a medium for communication to the public such as advertising" could be a useful starting point. The concept could be expanded to include a temporal element, such that firms investing in Java-compatible technology could enforce affirmations of platform independence to the extent of their reliance. We tend to favor this approach, or any of a number of conceivable variations, over the relatively blunt hand of antitrust. ${ }^{123}$ Alternatively, ISO could insist either on owning the intellectual property rights to Java itself, on

$\overline{123}$ See McGowan, supra note __, at 836-841; Lemley \& McGowan, supra note __, at __. 
having a full license, or on an undertaking by Sun not to allow the branded standard to deviate materially from the "ISOxxxx conformant" standard. The Java ISO process is a first, and the boundaries of ISO governance and Sun's marketplace conduct must be traversed with care. At a minimum, we can say that if one day we find that we have traded Windows for Java, and Sun acts in ways that seem inconsistent with social welfare, its conduct as a monopolist with respect to the Java brand ought to be judged by reference to the market expectations it created in its effort to achieve that status.

\section{CONCLUSION}

Some consistent strands run through the various competitive alignments and possibilities recounted above. That the social value of the Internet lies in its ability to facilitate interoperation, and that the Internet is subject to network effects both in its infrastructure and in the software used to bring it to life, strongly implies a tendency towards standardization. That tendency in turn argues in favor of open access to the standard or, put differently, a "standard" of interoperability. Such outcomes may be achieved through alteration of the various intellectual property rights at issue, through the marketing of proprietary products that facilitate interoperability, or perhaps both. Ideally, open systems such as Java will prevail in market competition, and the law need do nothing other than police the standards competition to ensure that the open standard is not somehow subverted.

These same factors imply a cautious approach to competition policy. In markets where standardization is desirable to consumers, suppliers with high market share are as likely to reflect maximization of social welfare as a threat to social welfare. Market share should not be taken in and 
of itself as a trigger for antitrust law. The focus must instead be on anticompetitive conduct and, more specifically, conduct that threatens to impede innovation or interoperability, or to increase transition costs. Where conduct threatens to have such effects, antitrust may enhance social welfare by ensuring a fair competition between standards.124 By the same token, where conduct does not pose a threat to interoperability antitrust is unlikely to improve upon market outcomes. And where antitrust could create an open standard only by altering the fundamental rules of intellectual property law, there may be good reasons outside of competition policy to leave intellectual property rights in place. 125

Thus, the best course for legal intervention in the operating system market (and its potential future derivative markets) is a narrow one. The law can and should encourage the development of open standards by holding Sun to its promises, and by allowing competition in the browser market to be driven by technology rather than Microsoft's license agreements. But it should not seek to choose a standard itself, or to deprive Microsoft or anyone else of its intellectual property rights. This "middle-of-the-road" answer is unlikely to satisfy Microsoft, Netscape or Sun; it is most closely in line with the measured approach the Antitrust Division has taken thus far. It doesn't guarantee a more competitive marketplace, but it does hold out the promise of one.

124 There are procedural as well as substantive caveats to this. Antitrust will enhance social welfare only where it can be invoked in a timely fashion. In a market that changes as quickly as the Internet does, this is a real problem. See Lemley, supra note __, at __.

125 At the same time, antitrust enforcers should properly be concerned about recent efforts to expand intellectual property rights beyond their historic bounds. The fact that such efforts have come in large part from the Clinton Administration, encouraged by software vendors, admittedly puts the Administration in a bit of an awkward position with regard to antitrust enforcement. 